\title{
First record of Pheidole indica Mayr, 1879 (Hymenoptera Formicidae) from Jordan
}

\author{
Antonio Scupola \\ World Biodiversity Association c/o Museum of Natural History Verona, Lungadige Porta Vittoria 9, 37129 Verona, Italy; \\ e-mail: scupolant@outlook.it
}

\begin{abstract}
The first record of the introduced ant Pheidole indica (Hymenoptera Formicidae) from Jordan is given. Brief comment on it diffusion and list of others introduced Pheidole Westwood 1839 in the Middle East are also given.
\end{abstract}

KEY WORDS Ant fauna; first citation; introduced species; Middle East.

Received 01.03.2021; accepted 18.06.2021; published online 30.06.2021

\section{INTRODUCTION}

Notoriously, the ants from Middle East are little studied, and despite this immense territory, it is very interesting. In fact, mountains, plains, steppes, and deserts that characterize it, present a large variety of habitats and environmental conditions, very different from each other. All these elements strongly influenced the composition of the local ant faunas, with Mediterranean, European, Boreoalpine, Central Asian and endemics species. Furthermore, several species are adapted to extreme dry condition in the deserted areas. Most studies on Middle East ants focused to Turkey, Israel and Saudi Arabia, while the knowledge on formicids from Iran, Iraq, Jordan, Lebanon, and Syria are unsatisfactory.

Concerning the Jordan Kingdom, the myrmecologists Borowiec \& Salata have recently published (2020) the first updated list on Jordan ants, supported by several new reports also. The list counts 87 species, a number not exhaustive but that in the next future others taxa it is very likely will be added.

In my personal collection (ASPC) are stored two soldiers of the genus Pheidole Westwood 1839
(Formicidae Attini), collected in Jordan, which I have determined as $P$. indica Mayr, 1879. I have used the keys of Eguchi (2004) and Sarnat et al. (2015) for the identification, and in particular to separate $P$. indica from the neighbour $P$. fervens, which it is easy to confuse it. Furthermore, I have used some specimens from my collection and pictures from Antweb.org., to compare the two species.

Pheidole indica is an introduced species, present in many countries of the world. In Middle East, data from Jordan (and Iraq also) are lacking so far (see Antmaps.org and the Jordan list of Borowiec and Salata where only P. koshewnikovi Ruzsky, 1905 and $P$. jordanica Saulcy, 1874, are reported), consequently $P$. indica from Jordan it is reported here for the first time.

\section{RESULTS}

Pheidole indica Mayr, 1879 (Fig. 1).

Material eXAmined. Jordan (Madaba), Dead Sea, coast NE, Maeen subdistrict, between the public beaches: Amman public beach resort and Crowne 
Plaza resort beach, 31.702N, 35.582E, 18.III.2019 leg. Platia G., 2 soldiers (ASPC, pins cod. \#2527,\# 2485).

REMARKS. The two specimens have some little differences compared to others $P$. indica. For example, the body is ochre-brownish in colour (as in Iranian or Madagascar populations) while in general the typical colouration of this species is brown or brownish-black. The vertexal lobes have straight longitudinal rugae (carinulae) reaching the posterior margin of head where very weakly blended out (similar head sculpture, I noted in specimens from California and in the synonyms $P$. teneriffana and P. strativentris (see pictures in Antweb.org)). Normally, the head of $P$. indica (and P. fervens also) have rugae straight but that often strongly blended out on the vertexal lobes. In addition, the anastomoses between the rugae in the posterior part of head are very short (in Asian populations the anastomoses are much longer and developed). The scrobes are narrow while in general are large and more sculpted by rugae and anastomoses, in particular in the South East Asian specimens. Finally, in dorsal view, the postpetiole appears widest and very much pointed at sides compared to other samples.

It is very likely that all these little differences will fall within the morphological variations of $P$. indica. I have excluded the similar species $P$. fervens because it is different in head sculpture, length of frontal carinae and shape of propodeal spines and postpetiole. Furthermore, the measurements confirm the identification as $P$. indica, also. In fact, the comparison of the maximum diameter of the compound eyes EL (0.208-0.224) with the length of penultimate antennal segment LASX $(0.152-0.160)$ match with that of $P$. indica where EL $>$ LASX, versus EL $\leq$ LASX in P. fervens (see Eguchi 2004, Ogata 1982). Furthermore, the scape index SI (54.2554.73) confirm $P$. indica (in fact in Fisher \& Fisher 2013 P. indica (as $P$. teneriffana) have range of $\mathrm{SI}=$ 49-62 versus 61-71 of $P$. fervens).

\section{DISCUSSION}

Pheidole indica (Fig. 1) is native from Indomalaya bioregion and belong to the fervens clade (Sarnat et al., 2015), an informal group that includes some Oriental and Australasian species. P. indica is an introduced species and reported from several areas across the world: Africa, Arabic Peninsula,
Australia, California, Caribbean islands, China, India Bangladesh, Japan, Korea, Mediterranean region, Malagasy region, Pakistan, Peru, Sri Lanka, West Indian Ocean islands (Wetterer, 2011; Fisher \& Fisher, 2013; Sarnat et al., 2015). In the Mediterranean area and Middle East, the occurrences of $P$. indica are very few. In Wetterer (2011), Borowiec (2014) and in Antmaps.org, the first citations and reports are known to be known to be Balearic islands, Canary islands, Greece, Crete, Egypt, England, Israel, Kuwait, Lebanon, Libya, Malta, Morocco, Oman, Pantelleria island, Saudi Arabia Spain, Tunisia, Turkey, Sicily, Syria, Yemen; United Arabs Emirates, Yemen and finally Jordan in the present work. To be noted that citations in general mostly refer to $P$. teneriffana Forel 1893 , taxon now considered synonym of $P$. indica (Sarnat et al., 2015).

Moreover, from my personal collection, I have two reports of $P$. indica that I added here: Greece: Corinth, Aghii Theodori, VIII.1993, leg. Scupola, 1 soldier and 1 worker dry mounted (\# pins code 291); Italy: Sicily, Syracuse city, neighbourhood Ortigia 10.IX.2020, leg. Scupola, colony 20.257A (in alcohol), and 1 soldier and 2 workers dry mounted (pins code \# 2480)

The spread of $P$. indica, as other introduced species, are often associated with commercial trade of plants. Sarnat et al. (2015) placed this species in the category D2 of the classification of Balckbourne et al. (2011) that includes those species that after the introduction in a place (in general about disturbed areas) are able to adapt to local environments. In this case, the success of the adaptation of $P$. indica mostly depend from its polygyny (true or facultative) and polydomy (Sarnat et al., 2015).

Until now in the areas where $P$. indica is been introduced, not result in competitions with the indigenous ants and no great negative impacts on the faunas are observed (Sarnat et al., 2015). The nests are in the soil often under stones or near dry stonewalls in open and dry habitats; the workers foraging in column (pers. observ.).

\section{Other Pheidole in Middle East}

Pheidole is a second hyper-diverse ant genus with around 1500 species, most living in the tropical areas of the world. Poorly represented in the temperate regions, from West Palaearctic to Central 


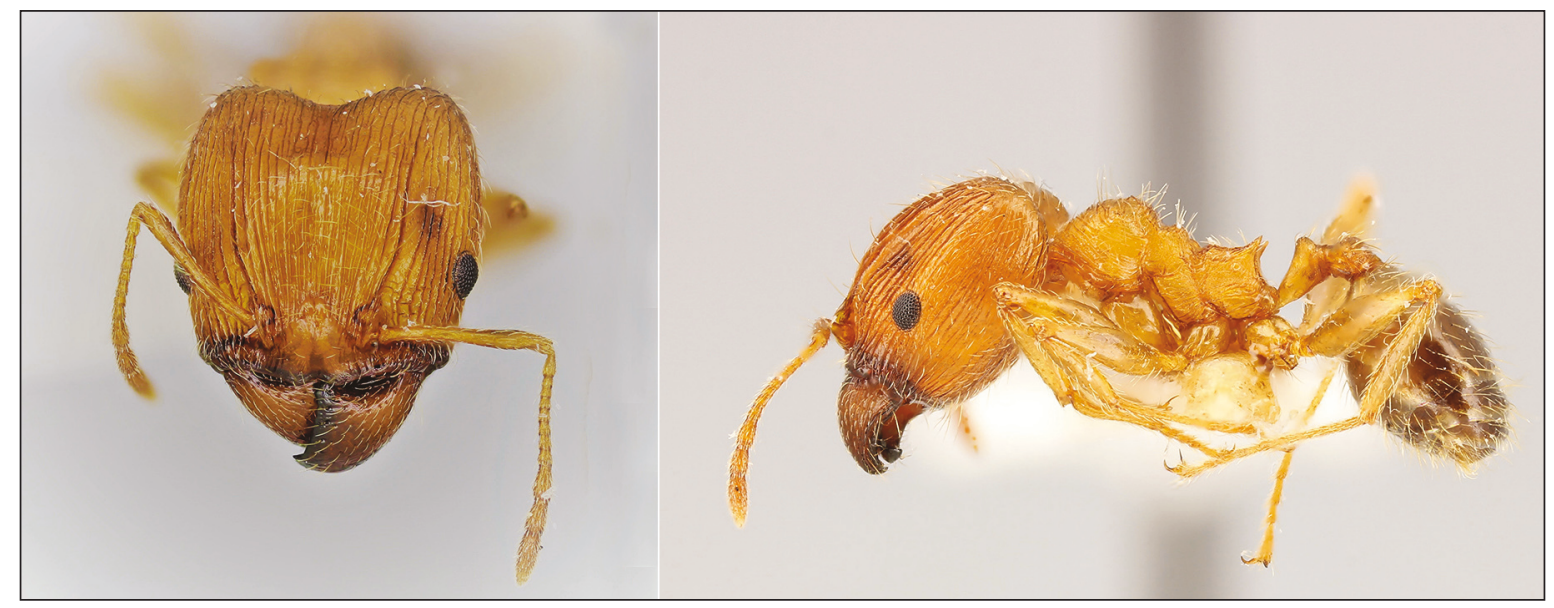

Figures 1, 2. Soldier of Pheidole indica from Jordan (specimen \#2527). Fig. 1: head (left). Fig. 2: body (right).

Asia, where the genus have a dozen of autochthones species only. Besides these, there are some introduced tropical Pheidole also, whose introduction is often temporary. Concerning the Middle East the genus Pheidole count the following species:

\section{Pheidole cicatricosa Stitz, 1917}

North West African species but reported from Israel and Iran also (Pashaei et al., 2018).

Pheidole jordanica Saulcy, 1874

North East African species reported from Egypt to Middle East and Saudi Arabia (Seifert, 2016).

Pheidole koshewnikovi Rusky, 1905

Cryptic species of the pallidula complex diffused from Balkan Peninsula to Central Asia (Seifert, 2016).

\section{Pheidole rugaticeps arabs Emery, 1881}

Yemenite endemic subspecies, but recently reported from Eritrea also (Madl, 2019).

\section{Pheidole sinaitica Mayr, 1862}

North East African species reported from Egypt, East Africa, Middle East and Arabic peninsula (Borowiec, 2014). Seifert (2016) speculates on the possible synonymy with P. jordanica.

Pheidole indica (Mayr, 1879).

Cosmopolitan Asian species (Middle East reports in introduction to present work).

Pheidole megacephala (Fabricius, 1793)

Cosmopolitan African species, reported from
Oman, Saudi Arabia, United Arabs Emirates, Yemen (Wetterer, 2012; Borowiec, 2014).

Pheidole katonae Forel, 1907

East African species reported from Oman and Saudi Arabia (Collingwood \& Agosti, 1996).

Pheidole lamellinoda Forel, 1902

Indian species introduced in United Arabs Emirates and in Socotra Island (Collingwood et al., 2004; Borowiec, 2014).

Pheidole minuscula Bernard, 1953

North West Africa species, reported from Israel and Saudi Arabia and Yemen (Abdoul Rassoul et al., 2013; Borowiec, 2014).

\section{Pheidole pallidula (Nylander, 1839)}

Nominal taxon of the pallidula species-complex, diffused in West Europe and Maghreb. The recent record from Socotra island (Sharaf et al., 2017) need confirmation because of possible misidentification with the other cryptic species of the complex.

Pheidole providens (Sykes, 1835)

Indian species reported from Egypt, Israel and Iran (Borowiec, 2014).

\section{Pheidole rugaticeps Emery, 1877}

East African species introduced in Saudi Arabia and Oman and Yemen (Collingwood \& Agosti, 1996) Saudi Arabia (Borowiec, 2014).

Pheidole parva Mayr, 1865

Asian species introduced in Arabic peninsula (Sharaf et al., 2018). 
Pheidole sculpturata Mayr, 1866

African species reported from Saudi Arabia (Collingwood, 1985), Yemen, Oman (Collingwood \& Agosti, 1996).

\section{Pheidole sp.}

Collingwood \& Agosti (1996) cited a single worker of an unidentified species collected in Yemen (introduced?).

\section{ACKNOWLEDGEMENTS}

Many thanks to A. Platia (Cesena, Italy) collector of the specimens of Pheidole indica and Luca Toledano (Verona, Italy) for the help in English translation. In addition, I extend my gratitude to Katsuyuki Eguchi (Metropolitan University of Tokyo, Japan) for the tips on my determination. Finally thanks at the anonymous referees for your useful comments.

\section{REFERENCES}

Abdoul-Rassoul M.S., Alii H.B. \& Razzaq R.S.H., 2013 New records of unidentified ants worker (Hymenoptera, Formicidae: Myrmicinae) stored in Iraqi Natural History Museum with key to species. Advances in Bioresearch, 4: 27-33.

Ant.Maps, 2020. Available from:

$<$ https:/www.antmaps.org. Accessed on: 23.09.2020

Antweb. 2020. Version 8.47. California Academy of Sciences, online. Available from: https:// www.antweb.org. Accessed on 23.09.2020.

Blackbourne T.M., Pyśek P., Bacher S., Carlton J.T. \& Duncan R.P., 2011. A proposed unified framework for biological invasions. Trends in Ecology and Evolution, 26: 333-339. https://doi.org/10.1016/j.tree.2011.03.023

Borowiec L., 2014. Catalogue of ants of Europe, the Mediterranean basin and adjacent regions (Hymenoptera Formicidae). Genus - Monograph Wroclaw, 25: 1-340. https://doi.org/10.5281/zenodo.3733156

Borowiec L. \& Salata S., 2020. Review of ants (Hymenoptera: Formicidae) from Jordan. Annals of the Upper Silesian Museum in Bytom, Entomology, 29: $1-29$.

Collingwood C.A., 1985. Formicidae (Insecta: Hymenoptera). Fauna of Saudi Arabia, 7: 230-302.

Collingwood C.A. \& Agosti D., 1996. Formicidae (Insecta: Hymenoptera). Fauna of Saudi Arabia (part 2), 15: $300-385$.
Collingwood C.A., Pohl H., Guesten R., Wranik W., Van Harten A., 2004. The ants (Insecta: Hymenoptera, Formicidae) of the Socotra Archipelago. Fauna of Arabia, 20: 473-495.

Eguchi K., 2004. Taxonomic revision of two wide ranging Asian ants, Pheidole fervens and $P$. indica, and related species. Annalen des Naturhistorischen $\mathrm{Mu}-$ seums in Wien, 105: 189-209.

Fisher G. \& Fisher B.L., 2013. A revision of Pheidole Westwood (Hymenoptera, Formicidae) in the islands of the Southwest Indian Ocean and designation of a neotype for the invasive Pheidole megacephala. Zootaxa, 3683: 301-356. http://dx.doi.org/10.11646/zootaxa.3683.4.

Madl M., 2019. Notes on the ant fauna of Eritrea (Insecta: Hymenoptera, Formicidae): type specimens deposited in the Natural History Museum Vienna (Austria) and preliminary checklist. Annalen des Naturhistorischen Museums in Wien (B), 121: 9-18.

Ogata K., 1982. Taxonomic study of the ant genus Pheidole Westwood of Japan, with description of a new species (Hymenoptera, Formicidae). Kontyû, 50: 189-197.

Pashaei Rad S., Taylor B., Torabi R., Aram E., Abolfahi G., Asfari R., Borjali F., Ghatei M., Hediary F., Jazini F., Kiah V. H., Mahmoudi Z., Safariyan F. \& Seiri M., 2018. Further records of ants (Hymenoptera, Formicidae) from Iran. Zoology in Middle East, 64: 145159. https://doi.org/10.1080/09397140.2018.1442301

Sarnat E.M., Fischer G., Guénard B. \& Economo E.P., 2015. Introduced Pheidole of the world: taxonomy, biology and distribution. ZooKeys, 543: 1-109. https://doi.org/10.3897/zookeys.543.6050

Seifert B., 2016. Inconvenient hyperdiversity - the traditional concept of "Pheidole pallidula" includes four cryptic species (Hymenoptera, Formicidae). Soil Orgamism, 88: 1-17.

Sharaf M.F., Fisher B.L., Collingwood C.A. \& Aldawood A.S., 2017. Ant fauna (Hymenoptera, Formicidae) of the Socotra Archipelago (Yemen), zoogeography, distribution and description of a new species. Journal of Natural History, 51: 317-378. http://dx.doi.org/10.1080/00222933.2016.1271157

Sharaf M.R., Fisher H.M., Aldhafer A., Polaszek A. \& Aldawood A.S., 2018. Additions to the ant fauna (Hymenoptera, Formicidae) of Oman an updated list, new records and a description of two new species. Asian Myrmecology, 9: 1-38. https://doi.org/10.20362/am.010004

Wetterer J.K., 2011. Worldwide spread of Pheidole teneriffana (Hymenoptera, Formicidae). Florida Entomologist, 94: 843-847.

https://doi.org/10.1653/024.094.0417

Wetterer J.K., 2012. Worldwide spread of the African bigheaded ant Pheidole megacephala (Hymenoptera, Formicidae). Myrmecological News, 17: 51-62. 